\title{
On Physical and Chemical Characteristics of Poly (methyl methacrylate)Nanocomposites for Dental Applications. II
}

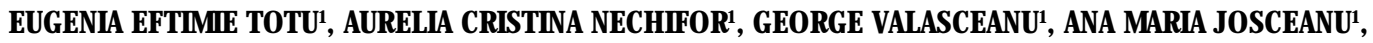
CORINA MARILENA CRISTACHE ${ }^{2 *}$

'University Politehnica of Bucharest, Faculty of Applied Chemistry and Material Science, 1-5 Polizu St, 11061 Bucharest, Romania ${ }^{2}$ Carol Davila University of Medicine and Pharmacy, Faculty of Midwifery and Medical Assisting (FMAM), Department of Dental Techniques, 8 Eroilor Sanitari Blvd., 050474 Bucharest, Romania

The ionic conductivity, ionic viscosity as intrinsic properties of PMMA - TiO nanocomposites were investigated. The PMMA doped with $0.4 \% \mathrm{TiO}_{2}$ nanoparticles has been used for 3D printed dentures manufacturing. A structural characterization using micro-computer tomography method was performed on 3D printed dentures, which have been permanently used for 12 months. The obtained results revealed good morphological stability of the materials in vivo, in the oral environment. The reinforced polymer matrix with nanotitania particles showed a dielectric constant and conductivity dependent on frequency, exhibiting improved characteristics when compared to the pure polymer matrix.
\end{abstract}

Keywords: 3D printed dentures, PMMA nanocomposite, ionic conductivity, ionic viscosity, micro-CT

Despite of the tremendous progresses registered in dental materials and technologies, poly (methyl methacrylate) (PMMA) remain the most widely used material in removable prosthodontics. Some of the drawbacks of the polymeric material used for complete dentures manufacturing were addressed lately by adding nano-fillers, either nanoparticles or nanotubes, or by utilizing new emerging technologies such as rapid prototyping or milling by computer numeric control (CNC). The introduction of computer-aided design and computer-aided manufacturing (CAD-CAM) for obtaining digital complete dentures came out with a significant number of advantages including reduced clinical chair time (2-3 appointments) for denture fabrication and placement, the ability to provide denture replacement in case of damage by using the stored digital data, high strength and density, lack of polymerization shrinkage of the acrylic resin when using polymer blanks and subtractive technique, reducing laboratory work time, among others [1]. The common method for fabrication of CAD-CAM complete dentures involves scanning of conventionally obtained records, digital prosthesis design, followed either by milling or rapid prototyping (3D printing) of monolithic or two-piece complete dentures [2-4]. When polymer blanks are used, the wastes of large quantities of denture base material lead to significantly increasing of the costs of CAD-CAM prosthesis [5]. Rapid prototyping (3D printing) is less expensive as subtractive technology and could present advantages over the CAD-CAM milling techniques. With additive manufacturing process, complex shapes with high accuracy can be obtained. However, several improvements are needed for providing long term stability of polymer structure, especially by adding important characteristics such as antibacterial properties [6,7].

It is known that the specific behavior of polymers to accommodate solvent molecules could be controlled and moderated through inorganic fillers. During recent years, most of such fillers are nanoparticles that impart to the polymeric matrix their specific properties, as a large active surface. PMMA in combination with nanotitania, was extensively used lately in dentistry, especially in removable prosthodontics due to its demonstrated improved characteristics [7-10].

However, before recommending nanotitania as additive to PMMA in standard procedures for complete denture manufacturing, studies regarding the structural stability over time in oral environment, are still needed. Color stability, clinical performance and complications were previously evaluated in vivo, with promising results $[2,11]$

Therefore, the aim of the present paper was to assess the structural characteristics of the 3D printed dentures based on PMMA doped with $\mathrm{TiO}_{2}$ nanoparticles after 12 months of continuous wearing. In addition, there will be presented a correlation of the specific parameters: ionic viscosity, permeability loss, impedance, ionic conductivity and viscosity for the PMMA-TiO 2 nanocomposite.

\section{Experimental part}

The PMMA-TiO ${ }_{2}$ nanocomposites have been prepared using poly (methyl metharcrylate) co-methyl methacrylate with benzoyl peroxide solution (eDent100) (EnvisonTEC $\mathrm{GmbH}$, Germany) and $\mathrm{TiO}_{2}$ nanopowder (anatase variety from Aldrich, Germany). Based on earlier results $[12,13]$ the recommended quantity of the titanium oxide nanoparticles to be added is $0.4 \%(\mathrm{w} / \mathrm{w})$. The polymeric solution and the corresponding nanotitania $(0.4 \% \mathrm{w} / \mathrm{w})$ have been sonicated in the ultra-sonication bath for $40 \mathrm{~min}$ for obtaining homogeneous PMMA nanocomposite according to the procedure introduced elsewhere [13].

The PMMA-TiO, nanocomposite have been characterized using the dielectric analyzer (DEA 288 Epsilon, Netzsch, Germany) and a Coated Tool Mountable Comb Electrode, with a sensing area of $254 \mathrm{~mm}^{2}$ and electrode spacing of $500 \mu \mathrm{m}$. The nanocomposite material has been irradiated using a UV exposure unit for printed circuit board manufacture and sealing, which emits UV radiation ranging from $290 \mathrm{~nm}$ to $320 \mathrm{~nm}$. The irradiation time was 25 min.

The dental prosthesis has been obtained through 3D printing technique with Envision TEC equipment (Germany). Denture manufacturing workflow [7] and the clinical 
protocol involving 35 fully edentulous patients (Bioethical Committee approval no. 98/2016, Clinical Trials. govldentifier:NCT02911038) were detailed presented in our previous published papers [2].

One of the 3D printed denture wear for 12 months has been investigated using the micro-computed tomography technique (micro-CT Scanner SkyScan 1272, Brucker). Micro-computer tomography analysis was performed on a high-resolution Brucker microCT SkyScan 1272 equipment. The sample was scanned with $0.25 \mathrm{~mm}$ filter, using a source voltage of $70 \mathrm{kV}$ and a current intensity of $130 \mu \mathrm{A}$, with an exposure time per frame of $850 \mathrm{~ms}$. Image pixel size was set at 7.5 um. Sample scanning was performed during $380^{\circ}$ rotation, with rotation step set to $0.25^{\circ}$ and average of 4 frame per slice. The reconstruction of the tomogram dataset was made using Brucker NRecon software.

\section{Results and discussions}

Figure 1 shows the variation of the main electrical parameters, namely: permittivity, loss factor, impedance, ionic conductivity and ion viscosity as function of time (min) for the PMMA-TiO ${ }_{2}$ nanocomposite during its UV curing at a temperature of $24^{\circ} \mathrm{C}$ (room temperature) at $1 \mathrm{~Hz}$ applied frequency. From this diagram, we note that the ionic viscosity increases, and its fluidity is decreasing with the increase of the UV exposure time. The corresponding ionic conductivity decreases also with the increase of the UV exposure time.
The viscosity and ionic conductivity are two macroscopic characteristics, connected to the polymeric chain segment mobility and ion mobility. While the viscosity measures the polymer's response to an applied stress field -as the UV radiation exposure, the ion conductivity gives the magnitude of ions' response to an applied electric field at a given frequency. There is an inverse relationship between viscosity and ion conductivity [13] that is related at its turn to the loss factor giving the total energy lost due to the ions' moving inside the composite, according to:

$$
\gamma=\frac{1}{\sigma}
$$

where: $\gamma$ is ionic viscosity and $\sigma$ is the ionic conductivity, at the same frequency.

Figure 2 presents the variation of the electrical and viscosity parameters for the studied nanocomposite with the UV curing time at $10 \mathrm{~Hz}$ frequency. From figure 2 we note that the bulk ionic conductivity decreases, and in same time the ion viscosity increases with the increase of the exposure time. Indeed, ionic conductivity and ion viscosity are reciprocal values. This means that the nanocomposite material presents a resistance increasing with an extended UV interaction [13]. In addition, the impedance curve suggests an increased electrical resistance [14]. It is easily noticed from the figures that the impedance increases with the increasing frequency.

The ionic conductivity could be expressed as function of the activation energy using an Arrhenius type equation:
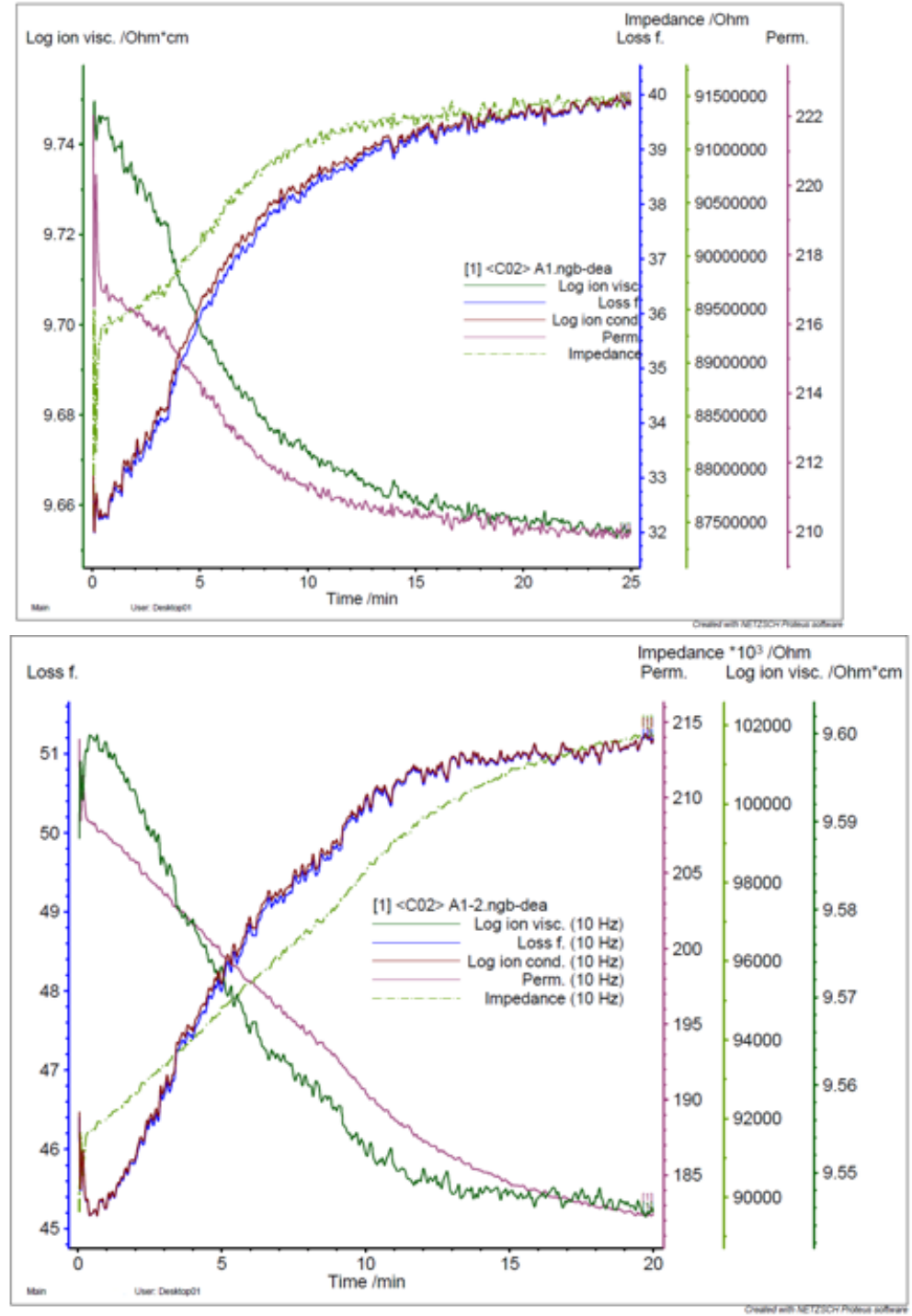

Fig. 1. Variation of the main characteristics of $\mathrm{PMMA}-\mathrm{TiO}_{2}$ nanocomposite during its UV curing at $1 \mathrm{~Hz}$ frequency, at room temperature
Fig. 2. Variation of the main characteristics of PMMA-TiO ${ }_{2}$ nanocomposite during its UV curing at $10 \mathrm{~Hz}$ frequency at room temperature 


$$
\sigma=\sigma_{0} e^{\frac{E_{a}}{k T}}
$$

where, $\sigma$ is the electrical conductivity, $\sigma$ is the preexponential factor, $\mathrm{k}$ is the Boltzmann constant $(8.62 \mathrm{x}$ $10^{-5} \mathrm{eV} . \mathrm{K}^{-1}$ ) while T is the absolute temperature $(\mathrm{K})$ and $\mathrm{E}_{\mathrm{a}}$ stands for the activation energy for ionic migration (eV).

If one-step chemical reaction is involved during the UV curing, the $E_{\text {could }}$ represent that activation energy able to quantify the minimum amount of energy needed to allow the complete reticulation to occur. The activation energy in the case of the nanocomposite is lower due to the presence of nanotitania particles. When UV radicalic mechanism is present, the situation might be more complex, because such process supposes few reaction steps consecutive or parallel, when each reaction have its own rate constant and activation energy. It is possible to consider an Arrhenius type relationship if there will be a single step process that is process rate limiting, controlling in this manner the overall process. As in real system, it is unlikely possible to verify such assumption, one could consider, in fact, that the activation energy $E_{a}$ is a quasiactivation energy. The PMMA nanocomposite photoreticulation under UV influence occurs under a time scale correlated with the cumulative UV dosage that could be considered as the total quantity of photons absorbed by the reticulating composite.

Figure 3 presents the specific characteristics of the $\mathrm{PMMA} \mathrm{TiO}_{2}$ nanocomposite at $100 \mathrm{~Hz}$. The permittivity, meaning the dielectric constant, which is one of the most importantelectrical properties of materials giving measure of the alignment and number of dipolar groups in the nanocomposite, was calculated and plotted. It should be noted the variation of the dielectric constant of (PMMA$\mathrm{TiO}_{2}$ ) nanocomposites with the frequency-athigher values of frequency the permittivity is slightly lower.

The figures show that the dielectric constant decreases with increasing of frequency. That could be assigned either to a decreased space charge polarization, either to a reduced presence of dipoles in the nanocomposite. The dielectric loss increased due to the presence of nanotitania, which brought a larger number of electrons in the whole nanocomposite structure and thus resulted into a higher electrical ion conductivity:

$$
\sigma=\varepsilon_{0} \omega \varepsilon^{\prime \prime}
$$

where $\sigma$ is the ion conductivity and $\varepsilon^{\prime \prime}$ is the loss factor.
The ion viscosity is an important characteristic for the behavior of UV polymerization of the nanocomposite. This parameter could describe the polymerizing processes. In addition, it correlates the polymerization with the dynamic viscosity. It could be observed that during first seconds of irradiation the ionic viscosity decreases, followed by a significant increase. We could consider on-set of the photopolymerization reaction the moment $30 \mathrm{~s}$ when the applied frequency was $1 \mathrm{~Hz}$. The on-set temperature increased with the increasing of the frequency values, reaching $1 \mathrm{~min}$ for $10 \mathrm{~Hz}$ and $2.4 \mathrm{~min}$ for $100 \mathrm{~Hz}$. The overall increase of the ionic viscosity for all applied frequencies was not high, being between 0.7 and 1.2 magnitude order. It is clear that the complete reticulation of our nanocomposite under UV radiation occurs within a very short time frame. During UV exposure, there will be necessary only $30 \mathrm{~s}$ (for $1 \mathrm{~Hz}$ ) until the ion viscosity increases, ending in a total decrease of about 1.2 orders of magnitude occurring after $11.7 \mathrm{~min}$.

As shown in our previous findings, the dispersion of titania nanoparticles into polymeric matrix is essential, as a higher dispersion generates an increased number of interfaces leading to superior interfacial polarization compared to a polymeric matrix with poor filler dispersion $[7,12]$. The addition of nanotitania did not modified the processability of the composite, such as an increased viscosity. The best flow ability and wettability of the PMMA$\mathrm{TiO}_{2}$ nanocomposite corresponded to the minimum ionic viscosity, while the higher constant ion viscosity put in evidence the reach of final fully reticulated state of the nanocomposite system. Thus, the nanocomposite reaches its final improved structure, completely reticulated. The ionic conductivity drops following the formation of the aggregated nanocomposite, while the viscosity increasing in connection with the ionic mobility limitation leads to complete cross-linking.

The 3D complete dentures manufactured from the $\mathrm{PMMA}_{-} \mathrm{TiO}_{2}$ nanocomposite $(0.4 \% \mathrm{w} / \mathrm{w})$ were structurally investigated after 12 months of permanent wear. Although there are competitive and spectacular techniques available for morphological investigations [15], an emerging imaging method, as micro-computed tomography (micro-CT) imposed itself for our studies. Micro-CT, a non-destructive 3D imaging tool at high resolution, was successfully used to investigate implants, bone, materials for bone augmentation, calcium phosphate cements or composite laminates [16,17]. In our study micro-CT was used to assessed the microstructure of the dentures manufactured

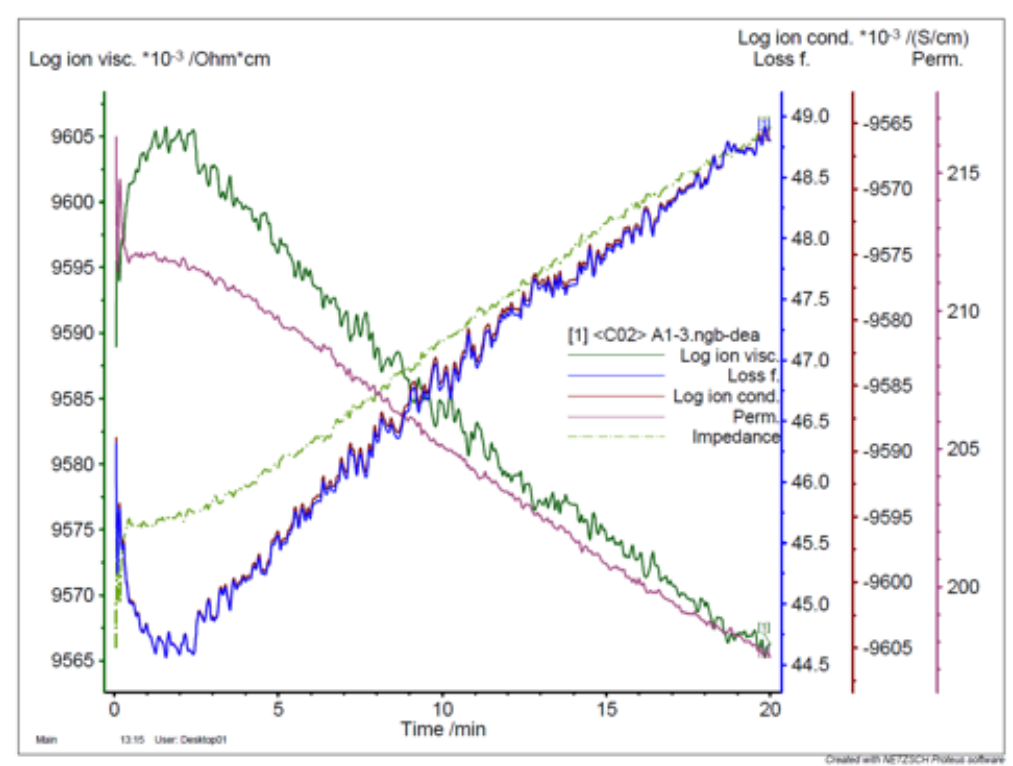

Fig. 3. Variation of the main characteristics of PMMA$\mathrm{TiO}_{2}$ nanocomposite during its UV curing at $100 \mathrm{~Hz}$ frequency, at room temperature 

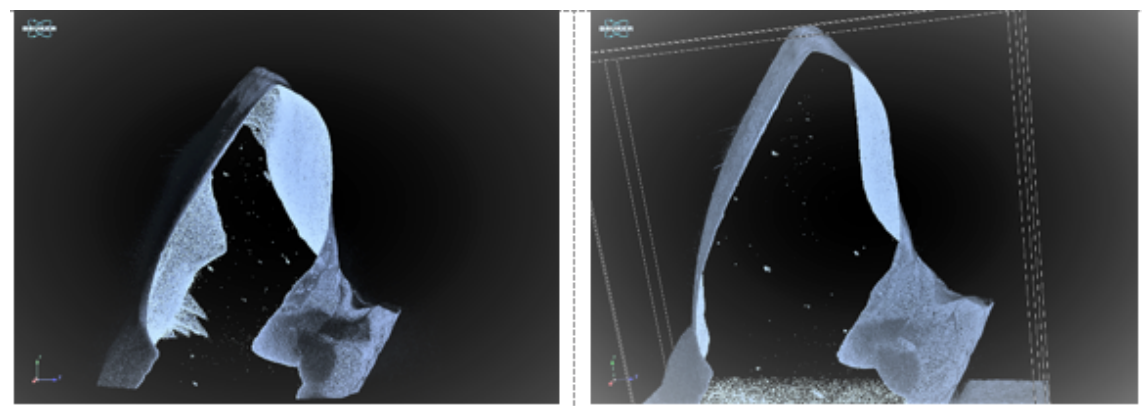

Fig. 4. Scanned area of 3D printed denture after 12 months of wear (grey scale image)

using newly obtained PMMA-nanoTiO, The main goal was to observe the occurrence of micro cracks in the material structure after being exposed for 12 months to the occlusal loads.

The results of micro-CT analysis, presented in figure 4, show unaltered structures of the 3D printed dentures. The 3D image stacks are reconstructed, using the reconstruction software (Bruker), from the image projections' rotation. Then, the images analysis provide qualitative information on the 3D printed denture structure [18]. The specific regions should be chosen, in a reproducible and consistent manner, taking into account the specific variation of the structure within the denture.

The denture analysis supposed the setting of a greylevel threshold, above which voxels should be considered background and below which voxels are considered materials. In addition, the noise has been removed using filters. The white spots are considered material points of high density, in our case the nanotitania particles. Taking into account the specific set up of the experiment, the image presented in figure 4 put in evidence the presence of nanotitania in the 3D printed denture. The morphology shows a relatively uniform distribution of the nanoparticles into the nanocomposite structure. Also, it should be noted that no pores, cracks or openings into the 3D printed structure occurred after 12 months of permanent wearing.

Due to the increased development of the additive manufacturing technologies, the tremendous changes brought by the use of nanoparticles in dental materials composition and the use of affordable equipment for 3D printing, comparing to the milling centers, rapid prototyping tends to become the preferred procedure for dentures fabrication. Despite the advantages provided by the new emerging technology, further clinical studies and patientcentered outcome measures have to be considered before replacing conventional complete dentures manufacturing.

\section{Conclusions}

The 3D printed denture using the PMMA composite with $0.4 \% \mathrm{TiO}$ exhibited an unaltered structure after 12 months of permanent wearing, proving better morphological stability compared to the simple PMMA denture.

The obtained results sustain our previous findings [12] according to which the ionic viscosity and permeability loss and impedance for the nanocomposites increases with frequency, while the ionic conductivity, the dielectric constantare decreasing due to the presence of the titanium oxide nanoparticles.

Acknowledgement: This work was supported by a grant of the Romanian National Authority for Scientific Research and Innovation, CCCDI-UEFISCDI, project number 30/2016 -PRIDENTPRO, (ERA-NETMANUNET II) within PNCDI III.
The micro computed tomography analyses on Scanner SkyScan 1272, Brucker were possible due to European Regional Development Fund through Competitiveness Operational Program 2014-2020, Priority axis 1, ProjectNo. P_36_611, MySMIS code 107066, Innovative Technologies for Materials Quality Assurance in Health, Energy and Environmental - Center for Innovative Manufacturing Solutions of Smart Biomaterials and Biomedical Surfaces -INOVABIOMED.Also, the authors wish to address warm thanks to Daniel Petre for professionally running the DEA analysis.

\section{References}

1. ALHELAL, A., ALRUMAIH, H., S., KATTADIYIL, M., T., BABA, N., Z., GOODACRE, C., J., J. Prosthet. Dent., 117, 2017,p.233.

2. CRISTACHE, C., M., TOTU, E., E., GROSU, A., R., ENE, O., BEURAN, I., A., BURLIBASA, M., Rev. Chim.(Bucharest), 70, no.2, 2019, p.387. 3. KATTADIYIL, M., T., ALHELAL, A., GOODACRE, B., J., J. Prosthet. Dent., 117, no. 6, 2017, p.721.

4. PANTAZI, A., TOTU, E., E., DOROBANTU, D., CRISTACHE, C., M., ENACHESCU, M., Mater. Plast., 55, no.4 ,2018, p.634.

5. KALBERER, N., MEHL, A., SCHIMMEL, M., MULLER, F., SRINIVASAN, M., J. Prosthet. Dent., 121, no.4, 2019, p.637.

6. TOTU, E., E., CRISTACHE, C., M., Rev. Chim.(Bucharest), 68, no.9, 2017, p.2102

7. TOTU, E. E., NECHIFOR, A. C., NECHIFOR, G., ABOUL-ENEIN, H.,Y., CRISTACHE, C. M., J. Dent., 59, 2017, p. 68.

8. TOTU, E. E., CRISTACHE, C. M., ISILDAK, I., YILDIRIM, R., BURLIBASA, M., NIGDE, M., BURLIBASA, L., Rev. Chim.(Bucharest), 69, no.5, 2018, p.1160.

9. CRISTACHE, C., M., TOTU, E., E., MOCANU, G., BUTNARASU, C., dentalTarget, 11, no.3, 2016, p.30.

10. TOTU, E., E., STANCIU, I., BUTNARASU, C., ISILDAK, I., CRISTACHE, C., M., E-Health and Bioengineering Conference, EHB, 2017.

11. CRISTACHE, C., OANCEA, L., DIDILESCU, A., BURLIBASA, M., TOTU, E., Rev. Chim.(Bucharest), 69, no.2, 2018, p.463.

12. TOTU, E. E., CRISTACHE, C. M., VOICILA, E., OPREA, O., AGIR, I., TAVUKCUOGLU, O., DIDILESCU, A. C., Mat. Plast., 54, no. 4, 2017, p.666.

13. TOTU, E. E., VOICILA, E., PISTRITU, V., NECHIFOR, G., CRISTACHE, C. M., Rev. Chim.(Bucharest), 69, no.1, 2018, p. 155.

14. TOTU, E., RUSE, E., LUCA, C., Rev. Chim.(Bucharest), 51, 2000, p.331.

15. TOTU, T., BUGA, R., M., DUMITRU, A., COSTACHE, M., SLADOJE, N., STANCIU, S., G., IEEE Access, 6, 2018, doi:10.1109/ ACCESS.2018.2868127.

16. IRIE, M., S., RABELO, G., D., SPIN-NETO, R., DECHICHI, P., BORGES, J., S., SOARES, P, B., F., Braz. Dent. J., 29, no.3, 2018, p.227.

17. MEHDIKHANI, M., NGUYEN, N., Q., STRAUMIT, I., GORBATIKH, L., LOMOV, S., V., IOP Conference Series: Materials Science and Engineering, 406, 2018.

18. TOTU, E. E., CRISTACHE, C. M., ISILDAK, S., TAVUKCUOGLU, O., PANTAZI, A., ENACHESCU, M., BUGA, R., BURLIBASA, M., TOTU, T., Mat. Plast., 55, no.4, 2018, p.616. 